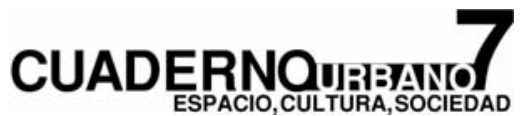

\section{LA INSEGURIDAD COMO DISCURSO Y RECURSO EN LA APROPIACIÓN Y USO DEL ESPACIO PÚBLICO}

\section{Julio de Freitas Taylor}

Antropólogo. Universidad Central de Venezuela. Especialista em Hábitat em Países Amazônicos. Universidade Federal do Pará (Ufpa). Belém, Brasil. Magister Scientiarium em Planificación Urbana. Instituto de Urbanismo. Universidad Central de Venezuela. Doctorante em Urbanismo. Instituto de Urbanismo. Universidad Central de Venezuela. Premio Nacional de Investigación en Vivienda 1994. Investigador del Swiss National Centre of Competence in Research (NCCR) y docente de la Universidad Central de Venezuela. Escuela de Antropología. 


\section{Artículos de Fondo}

Cuaderno Urbano. Espacio, Cultura, Sociedad - Vol. VII - № 7 (Octubre 2008) - pp. 215-231. ISNN 1666-6186

\section{Resumen}

En este artículo se pretende dar cuenta de cómo a partir de la inseguridad ciudadana vivida en Venezuela y, particularmente, en la ciudad de Caracas, se crean estrategias que van desde el aparente desuso de los espacios públicos, la concentración en espacios "purificados", hasta la privatización de calles y parques, a través de la creación de puestos de vigilancia privada y barreras físicas en muchas de las urbanizaciones de clase media y alta de la ciudad, legitimados como estrategias de autodefensa de los residentes frente a la ausencia de respuestas eficaces por parte de los organismos de seguridad municipales o estatales. Así también se busca discutir la creación de un discurso que criminaliza a los sectores más pobres de la ciudad y sobre los cuales se focalizan no sólo políticas públicas para enfrentar la inseguridad sino además estrategias privadas que giran en torno a la venta y consumo de todo tipo de dispositivos tecnológicos y simbólicos de protección.

Palabras Claves: Espacio público; Inseguridad urbana; Violencia; Ciudad; Ciudadanía.

\section{Abstract \\ Insecurity as discourse and resource in the apropiacion of public space}

This article tries to show how on the basis of the urban insecurity lived in Venezuela and, particularly, in the city of Caracas, strategies are created that go from the apparent disuse of public spaces, concentration in "purified" spaces, leading up to the privatization of streets and parks, through the creation of private security and physical barriers, in many of the middle and high class urbanizations. These are legitimized as strategies of selfdefense of the residents in opposition to the absence of effective replies on the part of the municipal or state security organizations. This approach also seeks to establish a discourse that criminalizes the poorest sectors of the city and focalizes not only on public policies to face the insecurity, but in addition private strategies that turn on the sale and consumption of all kinds of technological and symbolic protection devices..

Key words: Espacio público; Inseguridad urbana; Violencia; Ciudad; Ciudadanía. 
Julio de Freitas Taylor

La Inseguridad Como Discurso y ReCurso en la Apropiación y Uso del Espacio Público

\section{¿ESPACIO PÚBLICO O TIERRA DE NADIE?}

Existe un consenso entre los estudiosos de la ciudad del espacio urbano, es el que se refiere al importante lugar que juega el espacio público en la dinámica de las ciudades contemporáneas (BASSAND et al., 2001). Espacios como la calle, la avenida, la plaza, el centro comercial, constituyen, en general, territorios cargados de significado para las colectividades urbanas.

Ampliamente trabajado en sus aspectos materiales y técnicos por urbanistas y arquitectos, el espacio público se revela cada vez con mayor fuerza como un escenario de estudio para las Ciencias Sociales, como un lugar de relación y contacto.

Así, en las Ciencias Sociales, el estudio del espacio público se puede englobar en dos grandes ejes de discusión. En la primera acepción, trascendiendo el orden físico, se entiende el espacio público como el debate y la confrontación de ideas propuestas entre los miembros de un colectivo (HABERMAS, 1978) o como un “...marco mediático gracias al cual dispositivos institucionales y tecnológicos propios de las sociedades pos industriales son capaces de presentar a un público los múltiples aspectos de la vida social". (FERry, 1992).

En otro sentido, el espacio público se materializa en un territorio concreto, el cual hace posible el encuentro entre los actores urbanos y permite el acceso y la circulación a todos los lugares de la ciudad. (SENNET, 1978; JosEPH, 1988). Así, el carácter público o privado de un determinado lugar está dado no sólo por sus atributos morfológicos o espaciales, sino también por el tipo de funciones que alberga.

Para el urbanista catalán Jordi Borja (1998), éste último es también un concepto de orden jurídico, pues supone un espacio sometido a una regulación específica por parte de la administración pública, la cual es propietaria o posee el dominio del suelo, y garantiza su accesibilidad a todos y fija las condiciones de su utilización e instalación de actividades.

Desde la antropología, pudiéramos agregar a estos dos grandes ejes de estudio, la cuestión de la función identitaria del espacio publico: ¿cómo el espacio público constituye el 


\section{Artículos de Fondo}

Cuaderno Urbano. Espacio, Cultura, Sociedad - Vol. VII - № 7 (Octubre 2008) - pp. 215-231. ISNN 1666-6186

lugar por excelencia donde se pone en juego nuestro registro de identidades? Es allí donde constantemente el contacto con el otro permite captar la diversidad y, con ello, la posibilidad de reconocernos a nosotros mismos.

En estos espacios el sentido de lo lúdico, del comercio, de la fiesta, la violencia, la religión, el miedo se hallan presentes; por ello, los espacios públicos “...constituyen recursos importantes tanto para el despliegue de la autonomía individual como por la puesta en escena más o menos voluntaria, explícita y consciente de un modo de vida, de una pertenencia, de una adhesión o de un conflicto...Todo puede inscribirse en los espacios públicos: orden y desorden, seguridad y peligro, identidad y alteridad". (Voyé, citada en: BASSAND et al., 2001: 83).

El uso de la expresión "espacio público" se ha extendido a todos los ámbitos: desde el técnico hasta el hombre común identifican así el espacio que no ofrece restricciones en su acceso y donde, en teoría, es posible la expresión de sus derechos y de sus obligaciones en el escenario de la vida cotidiana; para los planificadores, en muchos casos, éste se limita a un marco legal concreto, minimizando sus dimensiones inmateriales, lo cual puede llegar a invisibilizar o esquematizar el valor cultural del concepto y las funciones que hacen de estos espacios un concepto integrador del hombre como ente natural y ser social.

El antropólogo Manuel Delgado, a través de la distinción entre dos términos que poseen aparentemente una relación de sinonimia perfecta: lo urbano y la ciudad, rescata el sentido del estudio del espacio público desde la antropología. Para ello señala que en una ciu$\mathrm{dad}$, podemos ver estructuras, articulaciones, instituciones, familias, iglesias, monumentos, centros, estaciones, etcétera, mientras que ninguna de esas cosas corresponde necesariamente a lo urbano, como lo demuestra el hecho de que todo ello haya estado antes en otros sitios. Al mismo tiempo, y en sentido contrario, la ciudad siempre está en la ciudad, mientras que lo urbano trasciende las fronteras físicas de ésta. (DeLGADO, 1999).

Desde este punto de vista, a diferencia de lo que sucede con la ciudad, lo urbano no es, entonces, un espacio que pueda ser habitado. La ciudad tiene habitantes, lo urbano no. Lo urbano está constituido por usuarios. Por ello, el ámbito de lo urbano, por antonomasia, su lugar, no es tanto la ciudad en sí misma como sí su espacio público. 
Julio de Freitas Taylor

La InSEguridad Como Discurso y Recurso en la Apropiación y Uso del Espacio Público

El espacio público es, entonces, un territorio en un constante vaivén de territorialización y desterritorialización, que se caracteriza por la sucesión y la creación inconsciente de relaciones fugaces e inestables entre las personas que lo recorren.

Pero, más allá de estas ideas iqué sucede cuando el espacio público es representado dentro del imaginario urbano como una "tierra de nadie"? Adónde se trasladan, entonces, esas funciones básicas y esenciales en la vida de los hombres. Tomemos, como ejemplo, una ciudad, la capital venezolana.

\section{CARACAS: MERCADO DEL MIEDO}

Caracas, cuya sola Área Metropolitana Interna, contemplada en cinco municipios que albergan alrededor de tres millones de personas, tuvo entre 2000 y 2001 un promedio de cinco homicidios diarios". Se ha convertido en la ciudad del "salir poco", del "no llegues tarde a casa", es también la ciudad de los más diversos sistemas de seguridad antirrobo en cada vehículo, desde las cadenas y candados que literalmente atan a éstos a la calle, las ensordecedoras alarmas, hasta los más sofisticados de protección satelital y de blindaje, con facilidades de pago para "garantizar su posibilidad de compra por cualquiera". Una capital donde el miedo ha hecho de ella su lugar de residencia, mientras el resto jura haber contemplado su rostro en cada uno de los desconocidos con los que se cruza en su transitar cotidiano.

Este miedo demanda cada vez más policías — por lo menos ocho distintas en la ciudad-, y ante la obsesión seguritaria, el mercado de la vigilancia privada conforma un verdadero ejército de personas armadas, en el que casi la mitad de las empresas que lo conforman se encuentran, irónicamente, en situación de ilegalidad, al no poseer los permisos operativos de la División de Armamento de la Fuerza Armada, organismo encargado de supervisar el parque de armas del país.

Este miedo se ha trasladado, asimismo, al ámbito de lo público, a través de la creación de puestos de vigilancia privada en muchas de las urbanizaciones de clase media y alta de la ciudad, los cuales restringen el libre acceso y tránsito en espacios de carácter público, pero que son legitimados, por un lado, como estrategias de autodefensa de los residentes
1- Fuente: Estadísticas de "Criminalidad Conocida". Cuerpo Técnico de Investigaciones Civiles Penales y Criminalísticas (CICPC). En total entre estos años se reportaron 3783 homicidios en los cinco municipios; destacan también en el mismo período: 9416 lesiones y 32423 hurtos $y$ robos de vehículos. 


\section{Artículos de Fondo}

Cuaderno Urbano. Espacio, Cultura, Sociedad - Vol. VII - № 7 (Octubre 2008) - pp. 215-231. ISNN 1666-6186

frente a la ausencia de respuestas eficaces por parte de los organismos de seguridad municipales o estatales, ante la progresión — real y simbólica - de la inseguridad urbana, y por otro, en términos de la búsqueda de un mayor estatus, por el carácter exclusivo que adquieren estas urbanizaciones, a través de lo que en términos de Richard Sennet, puede ser calificado como una "comunidad purificada" (SENNET, 1974).

Los miedos locales han sido aprovechados de manera global, y nuestro país no es precisamente una excepción, por el mercado de la seguridad. Tal como afirma Mike Davis, en una obra convertida en uno de los trabajos pioneros de los estudios sobre los cambios del espacio público en la ciudad:

"El mercado de la provisión de seguridad genera su propia demanda paranoide. La 'seguridad' comienza a ser un bien posicional definido por la posibilidad de ingresos para el acceso a 'servicios de protección' privados y a la pertenencia a enclaves residenciales o suburbios restringidos. Como símbolo de prestigio - y algunas veces como una frontera decisiva entre prosperidad y 'verdadera riqueza' - tiene menos que ver con la seguridad personal que con el grado de aislamiento personal en ambientes residenciales, laborales y de consumo y viajes de personas y grupos indeseables". (DAvis, 1999: 224).

Esto no sólo nos permite descifrar una de las características más comunes de las grandes ciudades. Más allá, nos ubica en uno de los chantajes más efectivos que el capital ha inyectado en la economía-mundo; ya hace algunos años Jean Baudrillard había advertido que:

“...nuestra compulsión obsesiva de seguridad puede interpretarse como una gigantesca ascesis colectiva, una anticipación de la muerte en la vida misma: de protección en protección, de defensa en defensa, a través de todas las jurisdicciones. Las instituciones, los dispositivos materiales modernos, la vida no es más que una triste contabilidad defensiva, encerrada en su sarcófago contra todo riesgo. Contabilidad de la supervivencia, en lugar de la radical contabilidad de la vida y de la muerte". (BAUdRILlard, 1980: 209).

Podríamos hablar, entonces, de una cultura en la que cada vez aparecen más miedos, una sociedad del "riesgo global", como ha sido llamada por Ulrich Beck (BECK, 2002), que ha convertido a las ciudades contemporáneas, en fortalezas rodeadas de enemigos no siempre identificables, contra los cuales los medios de comunicación y un enorme conjunto 


\section{Julio de Freitas Taylor}

La InSEguridad Como Discurso y ReCuRSo en la Apropiación y Uso del Espacio Público

de discursos de diversa índole, desde políticos hasta "científicos", previenen y amedrentan cotidianamente a una ciudadanía que haga lo que haga siempre estará "indefensa", y por lo tanto no escatimará en echar mano de cualquier instrumento a su alcance para neutralizar o aniquilar a quienes limiten o pongan en peligro su vida y sus bienes.

Extranjeros, extraños, hampones, narcotraficantes, guerrilleros, paramilitares, terroristas, hordas, huestes del mal, resentidos...la lista se hace casi infinita, y la prueba de su existencia va desde la experiencia individual, pasando por las leyendas urbanas, hasta las imágenes más crudas posibles que la televisión puede mostrar. "El mundo es uno solo, pero los enemigos son muchos", pareciera ser el eslogan, que surgió del discurso pos ll de septiembre. Algunos de estos peligros son conocidos localmente desde hace mucho, otros se agregan a la lista, a través de un complejo marketing global del miedo, se los rebautiza, pero también se los resemantiza, y en este juego de palabras se hacen, desde nuestro imaginario, pero no sólo desde éste, más fuertes y peligrosos.

Desde el voto y los más diversos mecanismos de control social, hasta las "iniciativas individuales" de los muros, las vallas, las alarmas, las rejas, hasta las armas blancas, de fuego, de electrochoque, y el spray defensivo. Todo vale cuando se trata de garantizar la "paz ciudadana".

En este contexto, casi apocalíptico, el espacio público tradicional parece ya no tener cabida. Una suerte de "vaciamiento", abandono y desuso de éste por parte de los sectores medios $^{2}$ y su transformación en no lugar, en el sentido dado por Marc Augé (1993), es la respuesta que la propia dinámica urbana ha generado y con ello la aparición de "especialidades inéditas" que han transformado la idea de ciudad en un croquis discontinuo de "lugares seguros", desconectados: la vivienda, el sitio de trabajo, el sitio de estudio, los "lugares sociales virtuales" y la concentración de actividades sociales y culturales en lugares con "seguridad garantizada", es lo que, de manera casi imperceptible, pero con gran impacto, la esfera pública ha sido tomada por grandes corporaciones transnacionales.

Así también, es notable, cómo el uso de plazas y parques, y en general de los llamados "espacios públicos", como puntos de encuentro y sitios de recreación, se ha venido sustituyendo por el de los malls y centros comerciales y por los locales de grandes cadenas de comida rápida, como Mc Donald's y Wendy's, entre otros.
2- Esto pudo ser comprobado por quien suscribe en una investigación realizada en el marco de la tesis doctoral. 


\section{Artículos de Fondo}

Cuaderno Urbano. Espacio, Cultura, Sociedad - Vol. VII - № 7 (Octubre 2008) - pp. 215-231. ISNN 1666-6186

3- Para Beck, siguiendo a George Simmel, el extraño es diferente al extranjero. El extraño se define por la exclusión en la proximidad, es decir hay una relación de distancia. Extraño quiere decir: "distanciamiento de los próximos de parte de los cercanos”. (Beck, 2000:131)
En medio de un proceso de apropiación del espacio público justificado en la poca eficacia de los organismos encargados de velar por la seguridad ciudadana y del desuso de otros, pareciera irse abriendo una suerte de sustitución de la función de esos espacios por parte de los locales comerciales:

"El comercio provee ahora lo que las instituciones urbanas y estatales han dejado de proveer: espacios civiles para el ocio y para el encuentro. Así como los centros comerciales, los espacios de vida se han convertido en suerte de bunkers; hacia afuera concreto y materiales densos, que dan la sensación de protección y seguridad" (RotKER, 2000:18)

Ello, sin embargo, se traduce en una situación cuyos efectos no necesariamente son del todo inocentes, a diferencia de algunas posturas, incluso de antropólogos, que reducen los centros comerciales como los nuevos espacios de socialización juvenil.

El desuso del espacio público a partir de su estigmatización como espacios peligrosos o desordenados por la explosión de la inseguridad, del comercio informal y ambulante, entre otras causas, junto con la falta de mantenimiento de éste, pareciera traer consigo un vaciamiento del espacio social en términos de lo que significa la ciudad como escenario de socialización y convivencia y con ello la transformación de estos últimos en

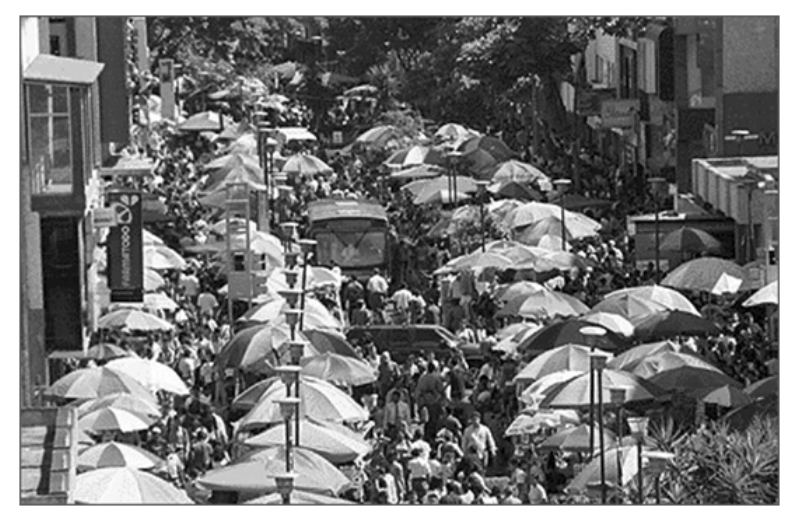
agujeros negros, en espacios hostiles para el poblador urbano, convirtiendo a la ciudad en un mundo de extraños, en el sentido usado por Ulrich Beck (BECK, 2000) ${ }^{3}$.

Así también, el sentimiento de inseguridad ya vivido por los habitantes de la ciudad se ve fuertemente reforzado por la elaboración discursiva-mediática de un otro, construido "a imagen y semejanza del miedo" (REguillo, 2000), al cual es posible culpar desde el punto de vista político, moral, e incluso estético de todo lo que ocurre en el espacio urbano, representado por los habitantes de los barrios ${ }^{4}$ populares de Caracas.

Imagen 1: Boulevard Sabana Grande y comercio informal, 2002. 


\section{Julio de Freitas Taylor}

La Inseguridad Como Discurso y Recurso en la Apropiación y Uso del Espacio Público

De esta manera se va desarrollando un proceso de construcción de una nueva doxa punitiva (WACQUANT, 1999) que criminaliza la pobreza, movido por una ideología económica y social basada en el individualismo y que ahora traducida en lo jurídico, se cristaliza en un efectivo y eficiente dispositivo de marketing ideológico con impacto mundial, en la que los barrios pasan a ser vistos como espacios incivilizados, que justifica, entonces, ante la opinión pública cualquier tipo de acción contra éstos, los pobres como clase, y no contra la pobreza como problema social. Estas acciones van desde la restricción de uso y circulación en algunos espacios públicos, la construcción de enclaves residenciales (GARRIDO y RAmos, 1994), hasta la creación de autodefensas ciudadanas e incluso la importación de políticas policiales de la ideología de la Tolerancia Cero, originaria de Nueva York, para así asegurar la vida y los bienes de los ciudadanos honrados.

Así también, el desplazamiento de la violencia hacia un grupo social determinado y, con ello, la presentación del habitante de barrio como un peligroso bárbaro que debe ser controlado y/o eliminado, por ser portador de un tipo físico y de una manera de hablar y vestir particular, o de lo que Fernández Durán ha llamado culpabilización por "porte de cara ilícita" (Fernández Durán, 1993).

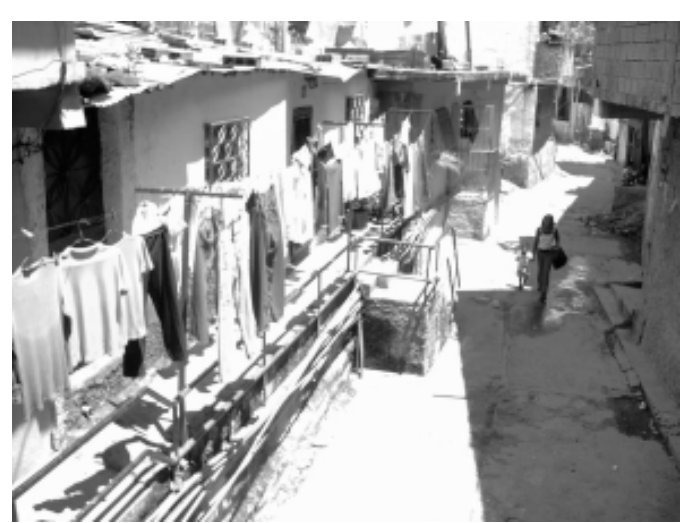

Imagen 2: Barrio pobre en San Bernardino, Caracas.
No es exagerado afirmar que ésta es la caracterización que generalmente se hace de los habitantes de los barrios populares. Salvajes, indios, monos y degenerados son sólo algunos de los adjetivos que se utilizan para definirlos; incluso es posible escucharlos en los propios pobladores de estas zonas para referirse a vecinos o miembros de otros barrios (De Freitas, 1995). A ello se suma la creencia de que los valores, la familia - tomando como modelo único la familia nuclear-y hasta el orden entre los asentamientos populares simplemente no existen ${ }^{5}$.
4- El término barrio se usa en Venezuela sólo para referirse a los asentamientos informales, por lo que sería equivalente a "favela", "villa miseria", etcétera.

5- Esta situación se ha visto fuertemente agravada en los últimos años en Venezuela, a partir de varios acontecimientos políticos: el primero de ellos ocurrido el 27 de febrero de 1989, bautizado como "día que los cerros bajaron”, en los cuales se produjeron fuertes disturbios en protesta por las medidas de ajuste económico, dictadas desde el Fondo Monetario Internacional e implementadas por el gobierno, con un saldo de víctimas nunca determinado. El segundo, el triunfo en las elecciones presidenciales de $1998 \mathrm{del}$ Teniente Coronel Hugo Chávez, actual presidente de Venezuela, quien participó en un frustrado golpe de Estado en 1992 y el cual posee, teóricamente, un amplio respaldo de los sectores populares. La lista de calificativos a los habitantes de los barrios populares se hizo más larga, agregándose algunos como hordas, turbas e invasores, entre otros, aumentando así el sentimiento de inseguridad y estableciendo una división discursiva en la ciudad de Caracas entre ricos y pobres espacializada entre el Este y el Oeste de la ciudad, aunque en la práctica esa división no se corresponda totalmente con la realidad política y económica de la ciudad. 


\section{Artículos de Fondo}

Cuaderno Urbano. Espacio, Cultura, Sociedad - Vol. VII - № 7 (Octubre 2008) - pp. 215-231. ISNN 1666-6186

6- De hecho, dentro del lenguaje policial venezolano, la categoría de "predelincuente" -al estilo de la película Minority Report-es utilizado para definir a los jóvenes que, por sus características socioeconómicas, pueden tener tendencia a cometer delitos. En declaraciones prestadas por el viceministro de Seguridad Ciudadana Belisario Landis, en 2000, éste admitía - no sin lamentarlo- el ajusticiamiento de más de 2000 predelincuentes por parte de los cuerpos de seguridad del Estado (Diario Tal Cual 27/10/2000).

\section{EL DEMONIO URBANO O LA CULPA ES DE LOS POBRES}

En el marco de estas representaciones dominantes de la violencia cotidiana, generadas en los medios de comunicación y reproducidos con diversos matices a lo largo de toda la trama social, la figura del malandro se ha consolidado como un personaje particularmente siniestro de la vida urbana venezolana. El malandro se ha convertido, entonces, en el imaginario urbano, en la principal causa de la inhabitabilidad de las ciudades venezolanas (Pedrazzin y SÁnchez, 1992; FerRándiz, 2001).

La constitución del estereotipo del malandro con el perfil genérico de cualquier joven habitante de las barriadas convierte de modo automático en presuntos delincuentes o predelincuentes ${ }^{6}$ a muchos jóvenes simplemente por el hecho de haber nacido, residir y/ o participar de las culturas típicas y claramente reconocibles de estas áreas estigmatizadas (De Freitas 1995).

Uno de los aspectos más relevantes de esta situación es la tendencia a convertirse en un problema global. Tal como lo expresa Borja (1998), pareciera que nuestro futuro urbano se caracterizará por ciudades con ejércitos protegiendo a los barrios civilizados frente a la barbarie popular.

También, en un reciente libro, la antropóloga brasileña Teresa Pires Caldeira (2000) indaga acerca de cómo, a partir del miedo, se han producido nuevas transformaciones urbanas en São Paulo durante las últimas dos décadas, generando un nuevo patrón de segregación espacial. En los últimos años, el dramático aumento de la violencia en esta ciudad y el fracaso de la policía y de la justicia en combatirla han tenido graves consecuencias: la privatización de la seguridad, el apoyo de acciones violentas e ilegales por parte de la policía y la reclusión por parte de las clases medias y altas en casas-fuerte.

Esta segregación, tal como lo indica Caldeira, no se limita al espacio privado, sino también al espacio público, produciendo una acentuación de las desigualdades sociales y la generación de prejuicios hacia los sectores más pobres.

Nos encontramos entonces frente a un proceso de transformación de lo público, expresada en un menor uso del espacio y de predominio de lo privado que reduce la ciudad tan 


\section{Julio de Freitas Taylor}

La Inseguridad Como Discurso y ReCurso en la Apropiación y Uso del Espacio Público

sólo a los espacios o vías de circulación que sirven a sus habitantes para desplazarse del lugar privado de la vivienda al trabajo o a los espacios seguros representados por los centros comerciales y otros lugares que pudiéramos calificar de seudo espacios públicos, en la medida en que el ciudadano - cuya práctica, la paideia, se desarrolla fundamentalmente en lo público, en el ágora - se va limitando, sin saberlo, apenas al papel de un visitante-consumidor, que debe ajustarse a las reglas del local en que se encuentra (SENNETT, 1974; Augé, 1993; GarCía Canclint, 1995; De Freitas, 2001).

Es el mundo que el sociólogo brasileño Lúcio Kowarick (1991) ha definido como del "ciudadano privado", término que, más que contradictorio, refleja la paradoja de una ciudadanía ejercida de manera minusválida, reducida a la encapsulación en el hogar y los asuntos personales. Con ello se genera además un aislamiento del exterior, capaz de hacer creer al individuo que la ciudadanía y los oficios políticos sólo son eficaces y reales si son vistos desde la televisión. Las personas se informan de su alrededor más cercano gracias a los medios de comunicación y no tanto mediante el uso social del afuera (MonsivaIs, 2000).

Esto nos ubica en un modelo particular de ciudadanía. Es el concepto de ciudadano ligado a la propiedad, en un sentido neoliberal. La organización vecinal y, con ello, la participación ciudadana se restringe a la defensa de la propiedad y la preservación de las condiciones de los espacios urbanos privilegiados.

Desde aquí, pareciera que las organizaciones vecinales (y con ello, el derecho a participar en la vida ciudadana) no pueden darse en los sectores populares, en los cuales los problemas no se definen por la defensa de la propiedad, sino por la necesidad de lograr lo que no se tiene. Desde el punto de vista político e ideológico, este asiento en la defensa de la propiedad implica la separación en relación con los sectores populares que son vistos como amenazas potenciales a la propiedad y a la seguridad. El cerramiento de las urbanizaciones tiene el propósito de lograr una seguridad que no puede garantizar el Estado, coadyuvando a una mayor segregación de los espacios urbanos.

Con todo, este proceso de desaparición de lo público no ocurre solamente, como pudiera pensarse en un primer momento, solamente en la llamada "ciudad formal". Por efecto del discurso - y las acciones - que focalizan la violencia urbana exclusivamente sobre los 


\section{Artículos de Fondo}

Cuaderno Urbano. Espacio, Cultura, Sociedad - Vol. VII - № 7 (Octubre 2008) - pp. 215-231. ISNN 1666-6186

7- Parece aventurado trasladar un concepto como el de espacio público, formulado básicamente desde el urbanismo par "ciudad formal" al escenario del barrio popular. Algunos

investigadores de este tipo de asentamientos como es el caso de Carlos Niño y Jairo Valderrama (Niño y Valderrama, 1997), frente a esta realidad hablan de "espacios públicos

fragmentados" o "retazos de espacio público", designaciones

éstas que, a nuestro juicio, establecen, sin proponérselo, comparaciones desequilibradas entre la realidad del barrio y el resto de la ciudad, quedando el primero en situación de minusvalía, frente a la aparente funcionalidad del espacio público urbano-formal. pobladores de los barrios populares, los habitantes de los barrios urbanos se enfrentan a la dificultad de acceder a algunos espacios públicos de la ciudad.

En años anteriores, estos habitantes respondieron a esta estigmatización intensificando el uso de los espacios existentes en sus delimitados territorios, lo cual siempre jugó un papel importante en la reconstrucción de la vida afectiva del barrio. No obstante, hoy en día, esta plasticidad entre lo público y lo privado se ha venido delimitando ante la fuerte inseguridad y violencia interna del barrio, la cual transforma la dinámica de uso tradicional de algunos de estos espacios, obligando también a sus habitantes a la reclusión en sus hogares, convertidos éstos en refugios, reduciéndose así el sentido y uso del espacio, produciendo una resemantización espacial que va desde el espacio público fantasmal, el espacio de la muerte, el espacio defensivo (Bolívar et al., 1994; Ontiveros, 1995).

Ello repercute en la identidad territorial que pueda tener el habitante con su entorno, viviendo hoy día procesos que se debaten entre el afecto y desafecto, apropiación y desapropiación con relación a sus espacios fundados.

A pesar de no poder hablar strictu sensu de espacios públicos en los barrios, sino más bien de espacios de uso común, tomando en cuenta las características de autoproducción de dichos espacios en las zonas de barrios ${ }^{7}$, éstos cumplen dentro del barrio funciones de gran relevancia; son espacios donde el imaginario social alcanza su concreción. Por ejemplo, las veredas peatonales, además de ser el camino obligado y el recorrido para tomar el transporte que lleva a muchos habitantes a sus trabajos, se convierten en algunos momentos del día en el espacio del juego para los niños y adolescentes. No obstante, estos mismos espacios, a otras horas - o incluso, permanentemente - pueden convertirse por medio de un violento proceso de apropiación o anulación de su calidad de público en espacios vacíos, espacios del terror, intransitables, controlados por las bandas que existen en el barrio y obligan a los transeúntes a tomar caminos alternos (Ontiveros, 1995; PedrazzinI y SÁncheZ, 1992; De Freitas, 1995; 2001).

A imagen y semejanza de lo que acontece en el resto de la ciudad o, para ser más precisos, en la ciudad formal, es posible encontrar en estos asentamientos un sentido de gradación o jerarquía cuya base se encuentra en el perfil topográfico del terreno. Vivir en la 


\section{Julio de Freitas Taylor}

La Inseguridad Como Discurso y Recurso en la Apropiación y Uso del Espacio Público

parte baja del barrio puede ser indicativo, aunque no de manera rígida, de un mayor estatus respecto de otros pobladores (amén de un mayor precio en el mercado inmobiliario formal o informal), de hecho, como la posibilidad de no asumirse como habitante de éste. Pero además implica también la probabilidad de un acceso más rápido a espacios públicos que no forman parte del barrio, tales como bulevares, centros comerciales, plazas, etcétera, no necesariamente más seguros y despejados, pero ciertamente menos estigmatizados, incluso por el mismo poblador.

Frente a este sistema de clasificación que se basa en la pura evidencia física, la única salida posible se vincula con la construcción de una diferencia o la invención de otra fachada ${ }^{8}$ para aumentar su cotización como grupo social. Así, es posible que en un determinado barrio, se estigmatice a un sector particular de éste, achacando a estos últimos toda la violencia o las características negativas que, desde la ciudad formal se endilgan a los pobladores en general $^{9}$.

\section{EPÍLOGO}

Pensar que el problema de la fragmentación de las ciudades y la pérdida del espacio público como escenario de socialización y de uso y disfrute citadino es un problema irresoluble en tanto la ciudad es un espacio demasiado heterogéneo para llegar a algún resultado satisfactorio, es simplemente un absurdo.

Si algún elemento caracteriza a la ciudad, en tanto entorno humano, es la heterogeneidad de cosmovisiones

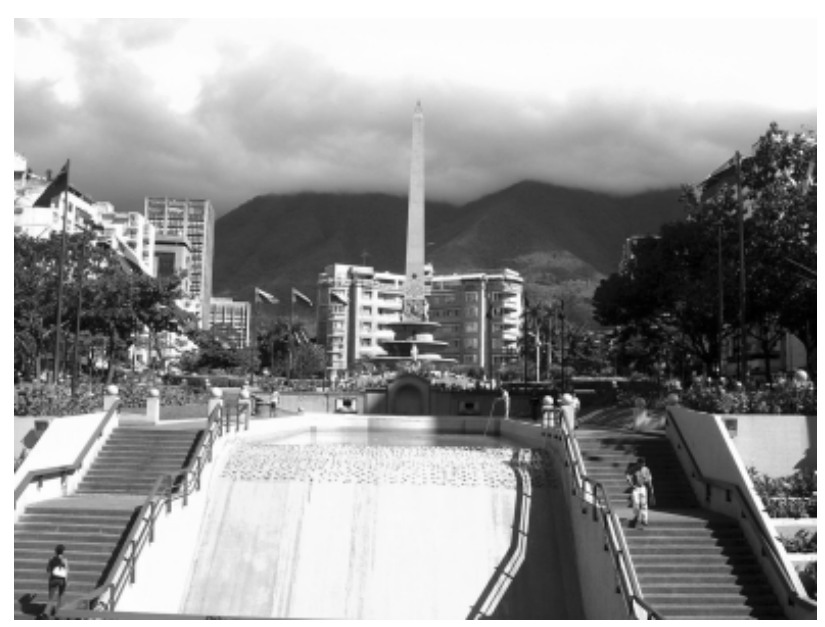

Imagen 3: Plaza Francia de Caracas, en una de las zonas más lujosas de la ciudad.
8- El término es de Erving Goffman, quien la define como: “...la parte del desempeño del individuo que funciona regularmente de forma general $y$ fija con el fin de definir la situación para los que observan la representación. La fachada por tanto, es el equipamiento expresivo, estereotipado $e$ intencional o inconsciente, empleado por el individuo durante su representación”. Cf. Erving Goffman. A

Representação do Eu na Vida Cotidiana. Petrópolis. Vozes, 1975. p. 29. Traducción nuestra.

9- En la investigación

"Densificación y Vivienda en los Barrios Caraqueños,

coordinada por Teolinda Bolívar en 1993, pudimos observar cómo mientras los habitantes de una calle en el barrio Carpintero de Petare, la calle Lara, decidieron restringir el acceso a ésta, convirtiéndose en un barrio cerrado, ante la violencia y robo que provenían del resto del barrio, los habitantes del Carpintero señalaban como culpables de la violencia y los

robos en la zona a quienes vivían en la calle Lara. 


\section{Artículos de Fondo}

Cuaderno Urbano. Espacio, Cultura, Sociedad - Vol. VII - № 7 (Octubre 2008) - pp. 215-231. ISNN 1666-6186

que ella alberga y la formación de las diferentes identidades, que en constante lucha entre unas y otras, con sus expresiones materiales e ideales, se producen en el seno de ésta.

Por ello, la antropología urbana, desde una óptica transdisciplinaria, debe estar llamada más que al estudio de casos particulares, que se traduzcan en mera curiosidad antropológica, al fomento de un proceso educativo centrado en la creación de un proyecto colectivo de ciudad, que fomente la posibilidad de búsqueda de un actor social que sea un sujeto colectivo estructurado a partir de una conciencia de identidad propia, sujeto, además, portador de valores y poseedor de un cierto número de recursos que le permitan actuar en el seno de una sociedad para defender los intereses de los miembros que lo componen y/o de los individuos a los cuales representa.

Ello sólo es posible a través de la creación de un nuevo pacto social urbano, capaz de permitir la construcción de un nuevo marco teórico que promueva una verdadera reforma del liberalismo político aún predominante en la interpretación del fenómeno de la urbanización, que asuma como mínimo ético la defensa constante de los derechos del ciudadano, que son, a nuestro modo de ver, la base misma del régimen democrático.

\section{BIBLIOGRAFIA:}

AGIER, Michel. (1999). L'invention de la ville. Banlieues, townships, invasions et favelas. Paris. Editions des Archives Contemporaines.

AGUILAR, Miguel; SEVILLA, Amparo y Abilio VERGARA. (2001). La ciudad desde sus lugares. Trece ventanas etnográficas para una metrópoli. México. Universidad Autónoma Metropolitana/Conaculta.

AUGÉ, Marc. (1993). Los no lugares. Espacios del anonimato. Una antropología de la sobremodernidad. Barcelona. Gedisa.

BAUDRILLARD, Jean (1980). El intercambio simbólico y la muerte. MonteAvila. Barcelona.

BASSAND, Michel et Alt (2001). Vivre et creer l'espace public. Lausanne. Presses polytechniques et universitaires romandes.

BECK, Ulrich. (2002). La sociedad del riesgo global. Madrid. Siglo XXI de España Editores. . (2000). La democraciay sus enemigos. Barcelona. Paidós. 
Julio de Freitas Taylor

La Inseguridad Como Discurso y Recurso en la Apropiación y Uso del Espacio Público

BOLÍVAR, Teolinda; GUERRERO, Mildred; ROSAS, Iris; ONTIVEROS, Teresa y DE FREITAS, Júlio (1994). "Densificación y vivienda en los barrios caraqueños". Contribución a la determinación de problemas y soluciones. Ministerio de Desarrollo UrbanoConsejo Nacional de la Vivienda. Caracas. (Premio Nacional de Investigación en Vivienda 1993).

BORJA, Jordi. (1998). “Ciudadanía y espacio público”. En: Revista Del Clad. Reforma y Democracia. Caracas. № 12. Octubre.

BORDIEU, Pierre. (1989). O poder simbolico. Difusão Editorial, Lisboa.

(1985) ¿Quésignifica hablar? Economíapolíticade los intercambios lingüísticos. Madrid, Akal.

CALDEIRA, Teresa. (2003). Ceidade de muros: Crime, segregação e cidadania em São Paulo. SÃO

PAULO, Editora 34/Edusp.

CARRANZA, Elías. (Coordinador). (1997). Delito y seguridad de los habitantes. México. Siglo XXI.

CORNEJO, Inés. (2001). "Plaza Universidad: i'estar' en un centro comercial es una manera de 'hacer' ciudad?" En: AGUILAR, Miguel; SEVILLA, Amparo y Abilio VERGARA. (2001). La ciudad desde sus lugares. Trece ventanas etnográficas para una metrópoli. México. Universidad Autónoma Metropolitana/Conaculta.

DAVIS, Mike. (1997). City of quartz. Los Angeles, capitale du futur. Paris, La Découverte. DAVIS, Mike. (1999). The ecology of fear. Los Angeles and the imagination of disaster. New York. Vintage Books.

DEL OLMO, Rosa. (2000). "Ciudades duras y violencia urbana”. En: Nueva Sociedad. Caracas. Mayo-junio. $\mathrm{N}^{\circ} 167$. pp. 74-86.

DELGADO, Manuel. (1999). El animal público. Barcelona. Anagrama.

(s/d). "La violencia como recurso y como discurso". Mimeo.

ECHEVERRIA, María y RINCÓN, Analinda. (2000). "Ciudad de territorialidades. Polémicas de Medellín". Medellín. Centro de Estudios del Hábitat Popular.

FERNÁNDEZ, RAMÓN. (1993). La explosión del desorden. La metrópoli como espacio de la crisis global. Fundamentos. Madrid.

FERRANDIZ, Francisco (1999). "Brevísima historia de E.H.: Espacios de trauma, estigma y peligro en las vidas de los niños y jóvenes de los barrios venezolanos". University of California at Berkeley. Mimeo.

FERRY, Jean-Marc et Alt. (1992). El nuevo espacio público. Barcelona, Gedisa.

FOUCAULT, Michel (2001). Vigilary castigar. Nacimiento de la prisión. México. Siglo XXI. 


\section{Artículos de Fondo}

Cuaderno Urbano. Espacio, Cultura, Sociedad - Vol. VII - № 7 (Octubre 2008) - pp. 215-231. ISNN 1666-6186

FREITAS, Júlio de (1995). "Bárbaros, armados y peligrosos: la eficacia del discurso sobre violencia popular urbana”. En AMODIO, Emanuele \& ONTIVEROS, Teresa (editores). Historias de identidad urbana. Composición y recomposición de identidades en los territorios populares contemporáneos. Caracas: Fondo Editorial Tropykos-Ediciones FACES, UCV.

FREITAS, Júlio de (2001). "Significado de casa y propiedad de la tierra en un asentamiento urbano autoconstruido". Caso Pantanal. Belém do Pará. Brasil. Trabajo de Grado presentado ante el Instituto de Urbanismo de la Universidad Central de Venezuela para optar al Título de Magíster Scientiarium en Planificación Urbana. Mención Política y Acción Local.

GARCIA CANCLINI, Néstor. (1990). Culturas híbridas. Estrategias para entrary salir de la modernidad. México. Grijalbo.

GARCIA CANCLINI, Néstor. (1995). Consumidores y ciudadanos. Conflictos multiculturales de la globalización. México. Grijalbo.

GARCIA SÁNCHEZ, Pedro. (2000). "Construction et conflicts d'urbanité dans les espaces publics à Caracas”. En: MONNET, Jérôme y Guénola CAPRON. (2000). L'urbanité dans les Ameriques. Les processus d'identification socio-spatiale. Toulouse. Presses Universitaires du Mirail. pp. 171-185.

JOSEPH, Isaac (1988). El transeúnte y el espacio público. Sobre la dispersióny el espacio público. Barcelona, Gedisa.

KLEINMAN, Arthur, VEENA Das \& Margaret LOCK (1997). "Introduction”. En Social Suffering. A. Kleinman,V. Das \& M. Lock eds., pp. ix-xxvii. Berkeley: University of California Press.

KOWARICK, Lúcio (1991). “Ciudad \& ciudadanía. Análisis de metrópolis del subdesarrollo industrializado". Nueva Sociedad. N-114.Caracas.

LE BRIS, Emile et Alt. (1984). Anthropologie de l'espace habite dans les villes africaines. Paris. Ministére de la Recherche et de la Technologie.

MAFFESOLI, Michel. (1984). Essais sur la violence. Banale et Fondatrice. Paris. Libraire des Méridiens.

MARQUEZ, Patricia y CASTILLO, Anabel. (1999) “iNuevas soluciones a viejos problemas?: Las Policías Municipales del Área Metropolitana de Caracas”. In: FERMENTUM. Revista Venezolana de Sociología y Antropología. Mérida (Venezuela). N-26. Pp. 355-882.

MONSIVAIS, Carlos. (2000). “Ciudadanía y violencia: Pesadillas al aire libre”. En: 
Julio de Freitas Taylor

La Inseguridad Como Discurso y Recurso en la Apropiación y Uso del Espacio Público

ROTKER, Susana. (Editora). (2000). Ciudadanías del miedo. Caracas. Nueva Sociedad. Pp. 231-235.

NIÑO MURCIA, Carlos \& CHAPARRO VALDERRAMA, Jairo (1997). "El espacio público en algunos barrios populares de la Bogotá actual". En CARVAJALINO BAYONA, Hernando (Director). "La calle. Lo ajeno, lo público y lo imaginado". Santa Fe de Bogotá: Documentos Barrio Taller (serie Ciudad y Hábitat).

ONTIVEROS ACOSTA, Teresa y Júlio de FREITAS. (1995). "Repensando el barrio: El papel del antropólogo en La rehabilitación de los espacios autoproducidos del Tercer Mundo" In: Bolívar, Teolinda y Josefina Baldó. La cuestión de los barrios. Homenaje a Paul-Henry Chaumbart de Lauwe. Caracas, Monte Avila.

ONTIVEROS, Teresa y Júlio de FREITAS. (1993). "Metrópoli y territorialización popular contemporánea". En: Urbana. Universidad Central de Venezuela. Instituto de Urbanismo. Facultad de Arquitectura, nº 13. p.p.69-76.

PEDRAZZINI, Yves \& SÁNCHEZ, Magaly (1992). Malandros, bandas y niños de la calle. Cultura de urgencia en La metrópoli latinoamericana. Valencia, Venezuela: Vadell Hermanos Editores.

REGUILLO, Rossana. (2000). "La cobstrucción social del miedo. Narrativas y prácticas urbanas”. En: ROTKER, Susana. (Editora). (2000). Ciudadanías del miedo. Caracas. Nueva Sociedad. P.p. 185-201.

ROJAS S., Edilsa \& GUERRERO G., Martha I. (1997) "La calle del barrio popular. Fragmentos de una ciudad fragmentada”. En Carvajalino Bayona, Hernando (Director) La calle. Lo ajeno, lo público y lo imaginado. Santa Fe de Bogotá: Documentos Barrio Taller (serie Ciudad y Hábitat).

URTEAGA, Maritza e Inés CORNEJO. “Los espacios comerciales: ámbitos para el contacto juvenil urbano". En: AGUILAR, Miguel; SEVILLA, Amparo y Abilio VERGARA. (2001). La ciudad desde sus lugares. Treceventanas etnográficas para una metrópoli. México. Universidad Autónoma Metropolitana/CONACULTA. Pp. 271-295.

SENNETT, Richard. (1974). El declive del hombre público. Barcelona, Península.

SILVA, Armando. (1992). Imaginarios urbanos. Bogotáy São Paulo: Cultura y comunicación urbana en América Latina Bogotá. Tercer Mundo.

VIVIESCAS, Fernando (1997). "Espacio público. Imaginación y planeación urbana”. En Carvajalino Bayona, Hernando (Director) La calle. Lo ajeno, lo público y lo imaginado. Santa Fe de Bogotá: Documentos Barrio Taller (serie Ciudad y Hábitat).

WACQUANT, Loic (1999). Les prisons de la misère. Paris, Raisons d' Agir. 
l

$1 L$

$\overline{7}^{\prime}$

$\mid \bar{F}$ 